\title{
Scleral Icterus
}

National Cancer Institute

\section{Source}

National Cancer Institute. Scleral Icterus. NCI Thesaurus. Code C122411.

Yellowing of the white part of the eyes, often due to a rise in bilirubin levels. 